\title{
Porphyrin Dimers Bridged by an Electrochemically Switchable Unit
}

\author{
Chi-Lun Mai ${ }^{[a]}$ Yi-Lin Huang, ${ }^{[a]}$ Gene-Hsiang Lee,${ }^{[b]}$ Shie-Ming Peng,${ }^{[b]}$ and \\ Chen-Yu Yeh*[a]
}

Dedicated to Professor Chi-Kwong Chang on the occasion of his 60th birthday

In the past decade much effort has been devoted to the synthesis and studies of molecular systems comprising porphyrin units bridged by well-defined $\pi$-conjugated spacers at the meso- or $\beta$-positions. ${ }^{[1-4]}$ These conjugated oligoporphyrin systems are expected to have potential applications in molecular wires and electronic devices due to their unique optical, physical, and chemical properties. Photophysical studies on electron transfer of a series of ferrocene-oligoporphyrin-fullerene triads show that a meso-meso butadiyne-bridged oligoporphyrin acts as an efficient molecular wire for long-range charge transfer over $65 \AA{ }^{[5]}$ More recently, the conductivity measurements on butadiyne-bridged porphyrin polymers indicate that the formation of doublestrand 4,4'-bipyridyl ladder complex by addition of bipyridine to the single-strand porphyrin polymer leads to an increase in conductivity by an order of magnitude. ${ }^{[6]}$ EPR studies performed by Therien and co-workers on mesomeso ethyne-linked porphyrin oligomers show that this type of conjugated molecules is able to mediate charge migration over a distance of about $75 \AA \AA^{[7]}$ The synthesis of mesomeso, $\beta-\beta, \beta-\beta$ triply-linked porphyrin tapes reported by Osuka represents a milestone in the area of porphyrin molecular wires. ${ }^{[3]}$ The fully conjugated porphyrin tapes exhibit remarkable properties including very low optical HOMOLUMO gap, low oxidation potential and rigid structure, and they may find use in a variety of molecular electronics.

[a] C.-L. Mai, Y.-L. Huang, Prof. C.-Y. Yeh

Department of Chemistry

National Chung Hsing University

Taichung 402 (Taiwan)

Fax: (+886) 4-2286-2547

E-mail: cyyeh@dragon.nchu.edu.tw

[b] Dr. G.-H. Lee, Prof. S.-M. Peng

Department of Chemistry

National Taiwan University

Taipei 106 (Taiwan)

Supporting information for this article is available on the WWW under http://www.chemistry.org or from the author.
Despite extensive studies on the conjugated porphyrin arrays, oligoporphyrin molecular wires that show switchable conductance states by chemical or electrochemical means are rare. One example is the porphyrin arrays in which the individual macrocyles are laterally-linked by a quinonoid unit at the $\beta, \beta^{\prime}$-positions of the porphyrin rings. ${ }^{[8]}$ In this system, the electronic communication between porphyrin units can be modulated by quinonoid/benzenoid conversion using chemical or electrochemical means. Another example of switchable porphyrin wires is the systems where proquinoidal units bridge two porphyrins. ${ }^{[9]}$ It is well known that the reversible conversion between quinone and hydroquinone can be achieved by chemical or electrochemical methods. ${ }^{[10]}$ Incorporation of a quinone unit into the central part of a porphyrin dimer via acetylene linkers would allow the interporphyrin interaction to be switched off and on in a controllable fashion and this type of molecules may have the potential for the application in switchable molecular wires. Therefore, we set out to design and synthesize a series of porphyrin dimers $\mathrm{Ni}_{2} 2, \mathrm{Ni}_{2} 3$, and $\mathrm{Ni}_{2} 4$ to explore their potential as redox-controllable switching molecules.

The synthetic routes to porphyrin dimers $\mathrm{Ni}_{2} \mathbf{2}, \mathrm{Ni}_{2} \mathbf{3}$, and $\mathrm{Ni}_{2} 4$ were outlined in Scheme $1 .^{[1]}$ The coupling reaction of porphyrin Ni1 with the diiodide gave porphyrin dimer $\mathrm{Ni}_{2}$ 2. $^{[12]}$ Demethylation of $\mathrm{Ni}_{2} \mathbf{2}$ to give $\mathrm{Ni}_{2} \mathbf{3}$ employing excess $\mathrm{BBr}_{3}$ was unsuccessful. However, the demethylation can be achieved by the reaction of excess $\mathrm{BBr}_{3}$ with the free base of the zinc analogue $\mathrm{Zn}_{2} \mathbf{2}$, obtained by a procedure similar to that for $\mathrm{Ni}_{2} 2$. $^{[13]}$ Subsequent nickel insertion afforded porphyrin dimer $\mathrm{Ni}_{2} 3$. The oxidation reaction of dimer $\mathrm{Ni}_{2} 3$ with $\mathrm{PbO}_{2}$ gave porphyrin $\mathrm{Ni}_{2} 4$. $^{[14]}$ For comparison purposes, porphyrin Ni5 was synthesized by employing a procedure similar to that for $\mathrm{Ni}_{2} \mathbf{2}$. The molecular structures of these porphyrins were confirmed by various spectroscopic methods such as NMR, UV/Vis, IR spectroscopy, and mass spectrometry.

Figure 1 shows the crystal structure of compound Ni5. ${ }^{[15]}$ The bond lengths and angles fall in the normal range. The porphyrin ring adopts an essentially planar conformation 

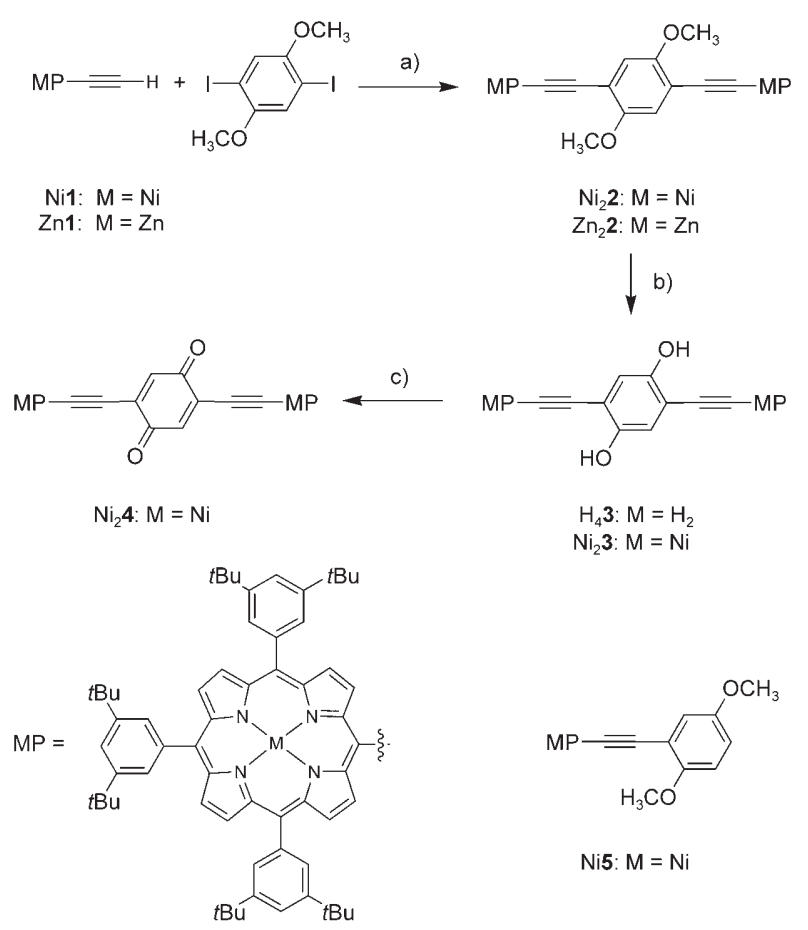

$\mathrm{Ni5}: \mathrm{M}=\mathrm{Ni}$

Scheme 1. Synthesis of porphyrin dimers. a) $\mathrm{AsPh}_{3},\left[\mathrm{Pd}_{2}(\mathrm{dba})_{3}\right], \mathrm{NEt}_{3}$ ( $\mathrm{Ni}_{2} 2,82 \% ; \mathrm{Zn}_{2} 2,89 \%$ ). b) i) $\mathrm{Zn}_{2} 2,20 \% \mathrm{HCl}, \mathrm{CH}_{2} \mathrm{Cl}_{2}$; ii) $\mathrm{BBr}_{3}, \mathrm{CH}_{2} \mathrm{Cl}_{2}$; iii) $\mathrm{Ni}(\mathrm{OAc})_{2} \cdot 4 \mathrm{H}_{2} \mathrm{O}, \mathrm{CHCl}_{3} / \mathrm{AcOH}\left(\mathrm{Ni}_{2} 3,43 \%\right.$ over 3 steps $)$; c) $\mathrm{PbO}_{2}$, $\mathrm{CH}_{2} \mathrm{Cl}_{2}(90 \%)$.

and is nearly coplanar with the dimethoxyphenyl ring. The coplanar arrangement can be ascribed to the crystal packing forces. ${ }^{[11,16]}$ It is possible that the two porphyrin rings and the bridge in dimers $\mathrm{Ni}_{2} \mathbf{2}$ and $\mathrm{Ni}_{2} 3$ are coplanar in the solidstate. The rigid and conjugated spacers in $\mathrm{Ni}_{2} \mathbf{2}$ and $\mathrm{Ni}_{2} \mathbf{3}$ would facilitate the electronic coupling between the porphyrin units although the spacers can undergo free rotation in solution.

The absorption spectra of porphyrin dimers $\mathrm{Ni}_{2} \mathbf{2}, \mathrm{Ni}_{2} \mathbf{3}$, and $\mathrm{Ni}_{2} 4$ and reference compound $\mathrm{Ni5}$ in THF are summarized in Figure 2 and Table 1. The spectrum of dimer $\mathrm{Ni}_{2} \mathbf{2}$ displays a quite similar feature to that of $\mathrm{Ni}_{2} \mathbf{3}$, suggesting that the dimethoxybenzene and hydroquinone units in $\mathrm{Ni}_{2} \mathbf{2}$ and $\mathrm{Ni}_{2} \mathbf{3}$, respectively, mediate the interporphyrin interaction in a similar way. As compared to that of $\mathrm{Ni}_{2} \mathbf{4}$, the Soret bands of $\mathrm{Ni}_{2} \mathbf{2}$ and $\mathrm{Ni}_{2} 3$ show peak-broadening and red-shift. The full width at half maximum (FWHM) is calculated to be $4386 \mathrm{~cm}^{-1}$ for $\mathrm{Ni}_{2} \mathbf{3}$, which is much larger than that for $\mathrm{Ni}_{2} 4\left(\mathrm{FWHM}=2098 \mathrm{~cm}^{-1}\right)$. It should be noted that $\mathrm{Ni}_{2} 4$ shows a broad band at $15965 \mathrm{~cm}^{-1}$ in THF, which shifts to $15210 \mathrm{~cm}^{-1}$ in a mixture of $\mathrm{CHCl}_{3} / \mathrm{MeOH}(2: 1)$, while the Soret and $\mathrm{Q}(1,0)$ bands are only slightly shifted (Figure S1 in the Supporting Information). Most likely this broad band consists of both the $\mathrm{Q}(0,0)$ band and charge transfer band from the porphyrin to the quinone unit. Further studies on the nature of this broad band will be continued. Comparison of the Soret band for porphyrin $\mathrm{Ni}_{2} 2$ with that for reference compound $\mathrm{Ni} 5$ confirms that peak-broadening of $\mathrm{Ni}_{2} \mathbf{2}$ is not induced by the electronic interaction between the porphyrin

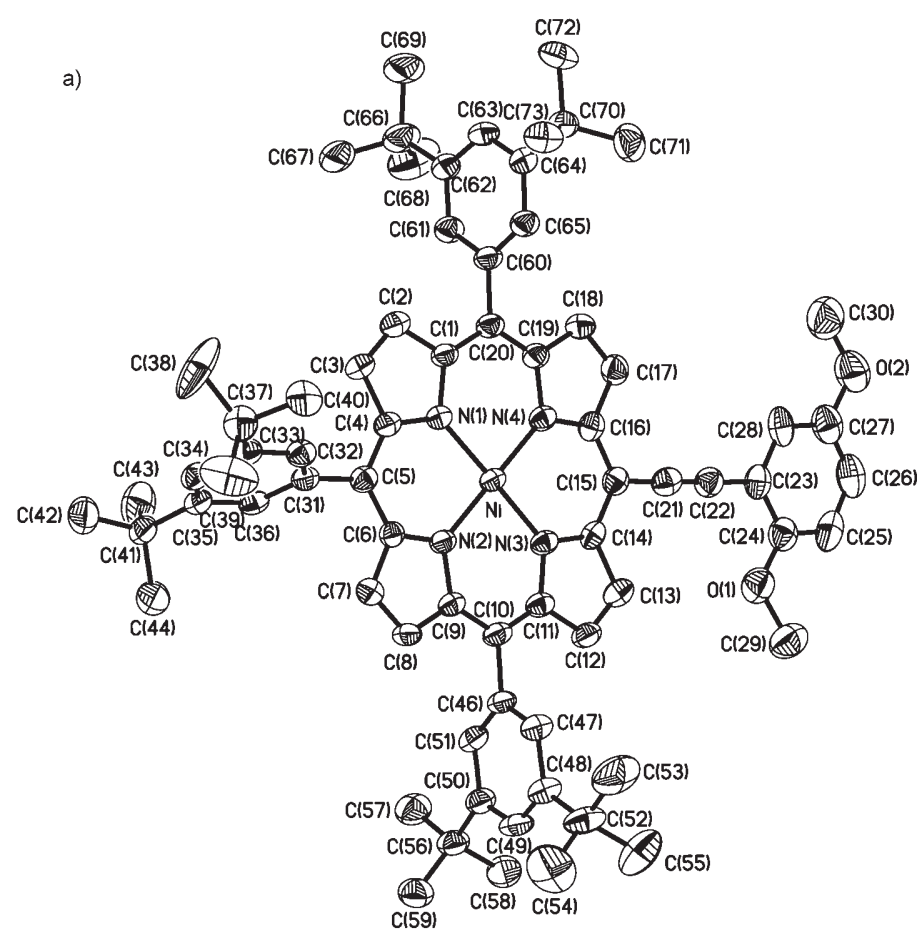

b)

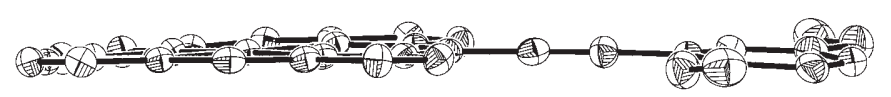

Figure 1. X-ray crystal structure of Ni5. a) Top view. b) Side view (mesosubstituted aryl groups omitted for clarity). The thermal ellipsoids were drawn at the $50 \%$ probability level.

and dimethoxylphenyl units. A significant increase in the intensity of $\mathrm{Q}$ bands for $\mathrm{Ni}_{2} 2$ and $\mathrm{Ni}_{2} 3$ relative to that for $\mathrm{Ni5}$ was observed. These spectral features for $\mathrm{Ni}_{2} \mathbf{2}$ and $\mathrm{Ni}_{2} \mathbf{3}$ can be explained by a decrease of the energy gap between HOMO and LUMO as a result of the extended $\pi$-conjugation and indicate that there is strong interporphyrin interaction mediated by the benzenoid unit. ${ }^{[17]}$ In the case of $\mathrm{Ni}_{2} \mathbf{4}$, the quinone bridge containing isolated double and single bonds effectively disrupt the electronic coupling between the two porphyrin ends.

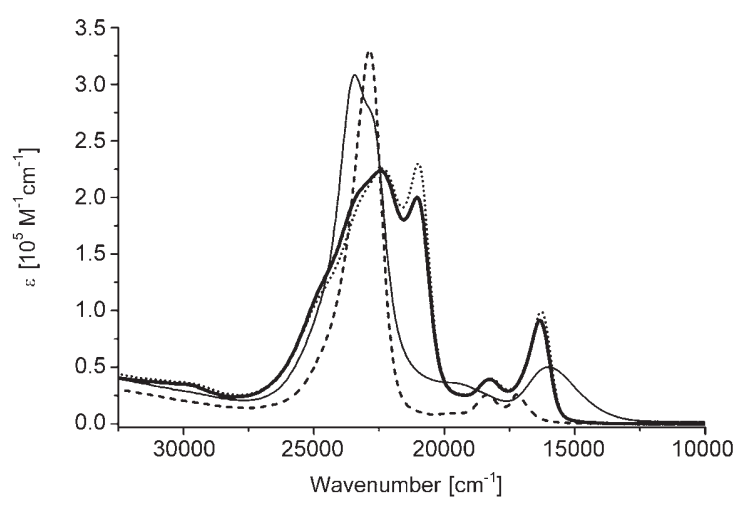

Figure 2. Absorption spectra of $\mathrm{Ni}_{2} \mathbf{2}(\cdots \cdot), \mathrm{Ni}_{2} 3(-), \mathrm{Ni}_{2} \mathbf{4}(-)$, and Ni5 (---) in THF. 
Table 1. Absorption data for porphyrins $\mathrm{Ni}_{2} \mathbf{2}, \mathrm{Ni}_{2} \mathbf{3}, \mathrm{Ni}_{2} \mathbf{4}$, and $\mathrm{Ni} \mathbf{5}$.

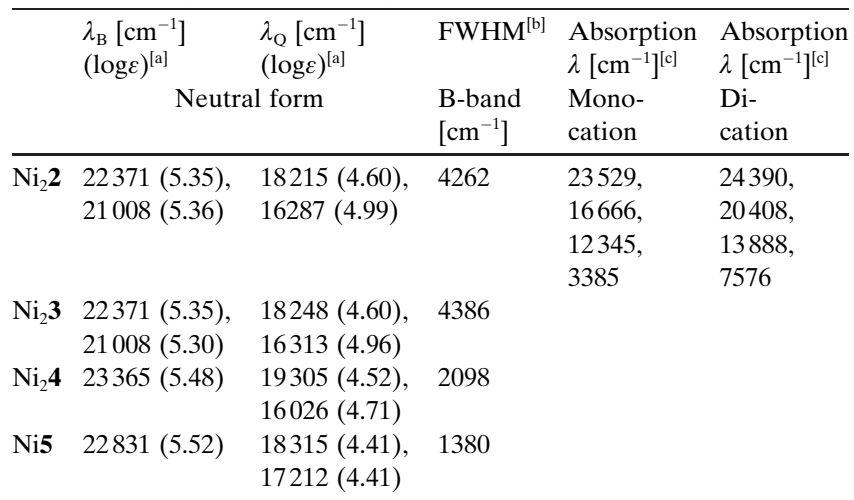

[a] The absorption spectra was taken in THF. [b] FWHM is the full width at half-maximum height. [c] The oxidized species of $\mathrm{Ni}_{2} 4$ and $\mathrm{Ni5}$ are relatively unstable.

A simple way to evaluate intramolecular interaction between the porphyrin units in porphyrin arrays is to study their electrochemical properties. It is anticipated that two one-electron oxidations for the first electron abstraction from the porphyrin units of $\mathrm{Ni}_{2} 3$ should be observed if the individual macrocycles are electrochemically coupled. However, the electrochemical reactions of dimer $\mathrm{Ni}_{2} \mathbf{2}$ instead of $\mathrm{Ni}_{2} 3$ were studied since the oxidation of the hydroquinone bridge in $\mathrm{Ni}_{2} \mathbf{3}$ occurs prior to that of the porphyrin rings and the 1,4-diethynyl-2,5-hydroxyphenyl and 1,4-diethynyl2,5-dimethoxyphenyl bridges in $\mathrm{Ni}_{2} \mathbf{2}$ and $\mathrm{Ni}_{2} \mathbf{3}$, respectively, should modulate the interporphyrin interaction in a similar way as evinced by the absorption spectra. The electrochemistry of $\mathrm{Ni}_{2} \mathbf{2}$ and $\mathrm{Ni}_{2} \mathbf{4}$ were investigated by cyclic voltammetry and differential pulse voltammetry. As shown in Figure 3, porphyrin dimer $\mathrm{Ni}_{2} \mathbf{2}$ exhibits two overlapping one-electron reversible oxidations at potentials of $E_{1 / 2^{-}}$ $(\mathrm{ox} 1)=+0.90$ and $E_{1 / 2}(\mathrm{ox} 2)=+0.99 \mathrm{~V}$, which are resolved by using differential pulse voltammetry, and a two-electron process at $E_{1 / 2}(\mathrm{ox} 3)=+1.27 \mathrm{~V}$. The first two one-electron oxidation processes can be assigned to successive formation of the monocation and dication, indicative of strong interporphyrin interaction in $\mathrm{Ni}_{2} 2$. The separation of the redox potentials $E_{1 / 2}(\mathrm{ox} 1)$ and $E_{1 / 2}(\mathrm{ox} 2)$ is $90 \mathrm{mV}$ and the comproportionation constant $\left(K_{\mathrm{c}}\right)$ was estimated to be $22 .{ }^{[18]}$ As compared to the 1,4-ethynylphenyl-bridged nickel porphyrin dimer, ${ }^{[19]}$ in which the first two one-electron oxidation potentials in $\mathrm{CH}_{2} \mathrm{Cl}_{2}$ at $298 \mathrm{~K}$ are separated by $50 \mathrm{mV}$, our porphyrin $\mathrm{Ni}_{2} 2$ shows a stronger electronic coupling between the porphyrin units via the bridge. This may be ascribed to the better energy proximity of the frontier orbitals of the porphyrin units and those of the 1,4-diethynyl-2,5-dimethoxyphenyl linker because the electron-donating nature of the methoxyl groups would elevate the energy of both HOMO and LUMO of the linker. The cyclic voltammogram of $\mathrm{Ni}_{2} 4$ (Figure 3) shows that the first two-electron oxidation occurs at $E_{1 / 2}=+1.08 \mathrm{~V}$ corresponding to the first electron abstraction from both the porphyrin rings to form $\mathrm{Ni}_{2} \mathbf{4}^{2+}$, indicating that the two porphyrin units do not show electronic coupling via the quinone bridge. The second two-electron oxidation corresponding to the formation of $\mathrm{Ni}_{2} 4^{4+}$ was observed at $E_{1 / 2}=+1.27 \mathrm{~V}$. In the reduction region, the first two oneelectron processes at $E_{1 / 2}=-0.26$ and $E_{\mathrm{pc}}=-0.72 \mathrm{~V}$ can be assigned to the reductions of the quinone unit and the twoelectron process at a potential of $-1.37 \mathrm{~V}$ corresponds to the first electron addition to both the porphyrin rings.

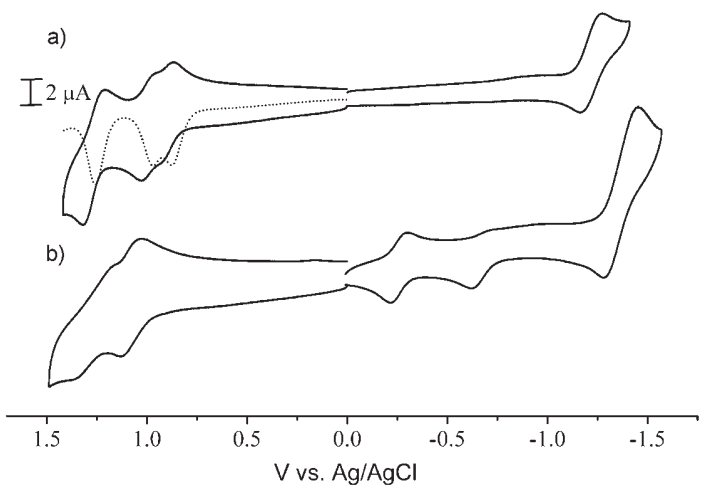

Figure 3. a) Cyclic voltammograms (-) and differential pulse voltammograms $(\cdots .$.$) for \mathrm{Ni}_{2} 2$ and b) cyclic voltammograms for $\mathrm{Ni}_{2} 4$ in $\mathrm{CH}_{2} \mathrm{Cl}_{2}$ containing $0.1 \mathrm{M} \mathrm{TBAPF}_{6}$ at a scan rate of $0.1 \mathrm{Vs}^{-1}$.

Calculations of molecular orbitals of $\mathrm{Ni}_{2} 2$ were performed by the PM3 method using Spartan '06 (Figure S2 in the Supporting Information). The building blocks used for the construction of $\mathrm{Ni}_{2} 2$ were taken from the crystal structure of porphyrin $\mathrm{Ni5}$, the symmetry of the molecule was unconstrained to $\mathrm{C}_{1}$. For $\mathrm{Ni}_{2} \mathbf{2}$, the electron density is significantly distributed to the $\pi$-system of both porphyrin rings and the bridge at the HOMO and LUMO, suggesting significant interaction between the two porphyrin rings, that is, the porphyrin units would behave as electrochemically dependent groups. In the case of the quinone-bridge dimer $\mathrm{Ni}_{2} \mathbf{4}$, the electron density of the HOMO is essentially localized on the two porphyrin rings and the LUMO is mainly contributed from the diethynylquionone unit. Furthermore, slight splitting $(0.1 \mathrm{eV})$ of HOMO and HOMO-1 for $\mathrm{Ni}_{2} \mathbf{2}$, which was absent in $\mathrm{Ni}_{2} \mathbf{4}$, was observed. These results are in a good agreement with the absorption spectra and electrochemical measurements.

To gain insight into the interporphyrin interaction in dimer $\mathrm{Ni}_{2} \mathbf{2}$, the oxidations were further investigated by electronic absorption. Figure 4 shows the UV/Vis-near IR spectra of $\mathrm{Ni}_{2} \mathbf{2}, \mathrm{Ni}_{2} \mathbf{2}^{+}$, and $\mathrm{Ni}_{2} \mathbf{2}^{2+}$. The monocation $\mathrm{Ni}_{2} \mathbf{2}^{+}$was generated in situ by reacting $\mathrm{Ni}_{2} \mathbf{2}$ with one equivalent of $\left[\left(p-\mathrm{BrC}_{6} \mathrm{H}_{4}\right)_{3} \mathrm{~N}\right]\left[\mathrm{SbCl}_{6}\right]$ in $\mathrm{CH}_{2} \mathrm{Cl}_{2}$. The corresponding dication $\mathrm{Ni}_{2} 2^{2+}$ can be generated by further addition of another equivalent of $\left[\left(p-\mathrm{BrC}_{6} \mathrm{H}_{4}\right)_{3} \mathrm{~N}\right]\left[\mathrm{SbCl}_{6}\right]$. Both monocation $\mathrm{Ni}_{2} 2^{+}$and dication $\mathrm{Ni}_{2} \mathbf{2}^{2+}$ are relatively stable since they can be converted back to the neutral form of compound $\mathrm{Ni}_{2} \mathbf{2}$ by reacting with a slight excess of ferrocene. In the near-IR region, the monocation $\mathrm{Ni}_{2} \mathbf{2}^{+}$displays a broad intervalence charge transfer (IVCT) band near the detection 
limit of $3385 \mathrm{~cm}^{-1}$, which disappears upon further oxidation to the corresponding dication $\mathrm{Ni}_{2} \mathbf{2}^{2+}$. In this porphyrin dimer system, the existence of the IVCT band upon oneelectron oxidation again demonstrates strong electronic coupling between the two porphyrin units. For comparison purposes, $\mathrm{Ni}_{2} 4$ and $\mathrm{Ni5}$ were oxidized under similar conditions and a broad IVCT band was not observed for the oxidized species (Figures S3 and S4 in the Supporting Information).

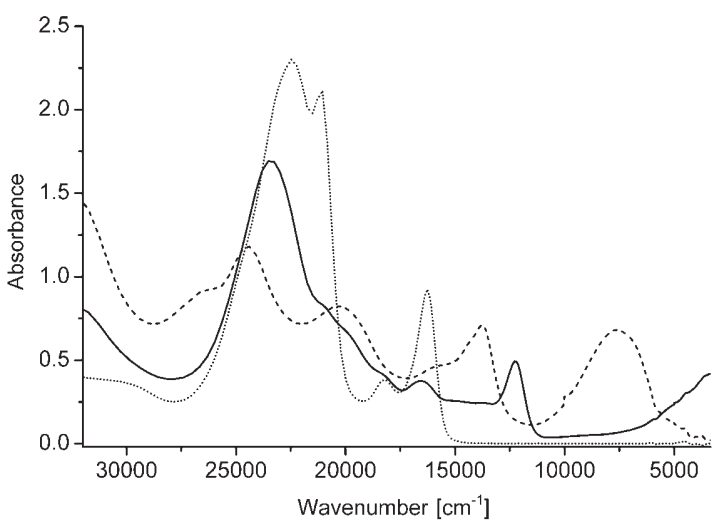

Figure 4. UV/Vis-NIR spectra of porphyrin dimer $\mathrm{Ni}_{2} 2(\ldots .$.$) , monocat-$ ion $\mathrm{Ni}_{2} \mathbf{2}^{+}(-)$, dication $\mathrm{Ni}_{2} \mathbf{2}^{2+}(-\cdots-)$.

We proposed a simple synthetic approach that allows us to incorporate a redox-active bridge into a porphyrin dimer. In comparison with those of dimer $\mathrm{Ni}_{2} \mathbf{4}$, the electronic absorptions of porphyrin dimers $\mathrm{Ni}_{2} \mathbf{2}$ and $\mathrm{Ni}_{2} 3$ exhibit significant peak-broadening and red shifts. The redox potentials of the first and second oxidations for $\mathrm{Ni}_{2} \mathbf{2}$, corresponding to the formation of $\mathrm{Ni}_{2} \mathbf{2}^{+}$and $\mathrm{Ni}_{2} \mathbf{2}^{2+}$ species, are separated by $90 \mathrm{mV}$. The mixed-valence species $\mathrm{Ni}_{2} \mathbf{2}^{+}$shows a broad IVCT band and this broad IVCT band disappears for $\mathrm{Ni}_{2} \mathbf{2}^{2+}$ species. These spectroscopic and electrochemical data confirm that the two porphyrin units in $\mathrm{Ni}_{2} \mathbf{2}$ and $\mathrm{Ni}_{2} \mathbf{3}$ exhibit strong electronic coupling while those in $\mathrm{Ni}_{2} \mathbf{4}$ are essentially independent. Thus, we propose that in dimer $\mathrm{Ni}_{2} 4$ the quinone bridge can be reversibly switched off and on by electrochemical or chemical means from cross-conjugated quinonoid to through-conjugated benzenoid states (Scheme 2). This type of porphyrin dimers holds promise to be used in the application of controllable molecular switches. Further studies on the switching properties of these porphyrin arrays and related analogues are underway in our laboratory.

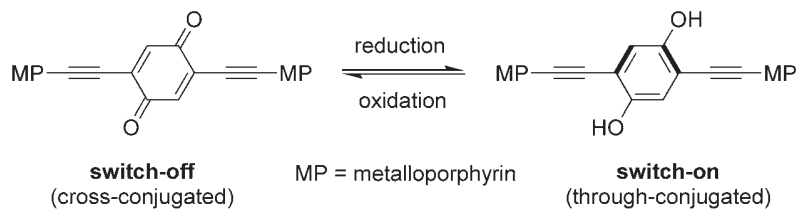

Scheme 2. Redox-controlled molecular switches.

\section{Acknowledgements}

The authors acknowledge the National Science Council of Taiwan for financial support. This work is supported in part by the Ministry of Education of Taiwan, under the ATU plan.

Keywords: conjugation • cross-coupling • electrochemistry • molecular electronics $\cdot$ porphyrinoids

[1] a) D. P. Arnold, R. D. Hartnell, G. A. Heath, L. Newby, R. D. Webster, Chem. Commun. 2002, 754-755; b) D. P. Arnold, G. A. Heath, J. Am. Chem. Soc. 1993, 115, 12197-12198; c) H. L. Anderson, S. J. Martin, D. D. C. Bradley, Angew. Chem. 1994, 106, 711-713; Angew. Chem. Int. Ed. Engl. 1994, 33, 655-657; d) M. Hoffmann, C. J. Wilson, B. Odell, H. L. Anderson, Angew. Chem. 2007, 119, $3183-$ 3186; Angew. Chem. Int. Ed. 2007, 46, 3122-3125.

[2] a) V. S.-Y. Lin, S. G. DiMagno, M. J. Therien, Science 1994, 264, 1105-1111; b) P. J. Angiolillo, V. S.-Y. Lin, J. M. Vanderkooi, M. J. Therien, J. Am. Chem. Soc. 1995, 117, 12514-12527; c) K. Susumu, M. J. Therien, J. Am. Chem. Soc. 2002, 124, 8550-8552; d) T.-H. Huang, Y.-J. Chen, S.-S. Lo, W.-N. Yen, C.-L. Mai, M.-C. Kuo, C.-Y. Yeh, Dalton Trans. 2006, 2207-2213.

[3] a) A. Tsuda, A. Osuka, Science 2001, 293, 79-82; b) D. H. Jeong, S. M. Jang, I.-W. Hwang, D. Kim, Y. Matsuzaki, K. Tanaka, A. Tsuda, T. Nakamura, A. Osuka, J. Chem. Phys. 2003, 119, 52375252 ; c) H. S. Cho, H. Rhee, J. K. Song, C.-K. Min, M. Takase, N. Aratani, S. Cho, A. Osuka, T. Joo, D. Kim, J. Am. Chem. Soc. 2003, 125, 5849-5860.

[4] a) F. Odobel, S. Suresh, E. Blart, Y. Nicolas, J.-P. Quintard, P. Janvier, J.-Y. L. Questel, B. Illien, D. Rondeau, P. Richomme, T. Häupl, S. Wallin, L. Hammarström, Chem. Eur. J. 2002, 8, 3027-3046; b) N. Hayashi, M. Murayama, K. Mori, A. Matsuda, E. Chikamatsu, K. Tani, K. Miyabayashi, M. Miyake, H. Higuchi, Tetrahedron 2004, 60, 6363-6383; c) D. A. Shultz, H. Lee, K. P. Gwaltney, J. Org. Chem. 1998, 63, 7584-7585.

[5] M. U. Winters, E. Dahlstedt, H. E. Blades, C. J. Wilson, M. J. Frampton, H. L. Anderson, B. Albinsson, J. Am. Chem. Soc. 2007, 129, $4291-4297$.

[6] F. C. Grozema, C. Houarner-Rassin, P. Prins, L. D. A. Siebbeles, H. L. Anderson, J. Am. Chem. Soc. 2007, 129, 13370-13371.

[7] K. Susumu, P. R. Frail, P. J. Angiolillo, M. J. Therien, J. Am. Chem. Soc. 2006, 128, 8380-8381.

[8] a) M. J. Crossley, L. A. Johnston, Chem. Commun. 2002, 1122-1123; b) K. Sendt, L. A. Johnston, W. A. Hough, M. J. Crossley, N. S. Hush, J. R. Reimers, J. Am. Chem. Soc. 2002, 124, 9299-9309.

[9] K, Susumu, T. V. Duncan, M. J. Therien, J. Am. Chem. Soc. 2005, 127, 5186-5195.

[10] M. Quan, D. Sanchez, M. F. Wasylkiw, D. K. Smith, J. Am. Chem. Soc. 2007, 129, 12847-12856.

[11] P. N. Taylor, A. P. Wylie, J. Huuskonen, H. L. Anderson, Angew. Chem. 1998, 110, 1033-1037; Angew. Chem. Int. Ed. 1998, 37, 986989.

[12] R. W. Wagner, T. E. John, F. Li, J. S. Lindsey, J. Org. Chem. 1995, 60, 5266-5273.

[13] G. A. Baker, F. V. Bright, M. R. Detty, S. Pandey, C. E. Stilts, H. Yao, J. Porphyrins Phthalocyanines 2000, 4, 669-683.

[14] M. Zora, B. Yucel, S. Acikalin, Tetrahedron lett. 2003, 44, 2237 2241.

[15] Crystal data of Ni5: crystals grown from $\mathrm{CHCl}_{3} / \mathrm{CH}_{3} \mathrm{OH}$. $\mathrm{C}_{73} \mathrm{H}_{81} \mathrm{C}_{13} \mathrm{~N}_{4} \mathrm{NiO}_{2}, M_{\mathrm{r}}=1211.48$, monoclinic, space group $C 2 c, a=$ 40.4192(14), $b=8.9943(3), c=41.0014(14) \AA, \beta=118.8853(9)^{\circ}, V=$ 13051.3(8) $\AA^{3}, Z=8, \rho_{\text {calcd }}=1.233 \mathrm{~g} \mathrm{~cm}^{-3}, T=150(2) \mathrm{K}, 27950$ measured reflections, 11498 unique reflections $\left(R_{\text {int }}=0.0699\right), R$ values: $R 1=0.0769, w R 2=0.1982 \quad(I>2.0 \sigma(I)) ; R I=0.0769, \quad w R 2=0.1982$ (all data), GOF $=1.028$. CCDC 668541 contains the supplementary crystallographic data for this paper. These data can be obtained free 
of charge from The Cambridge Crystallographic Data Centre via www.ccdc.cam.ac.uk/data_request/cif.

[16] H. L. Anderson, A. P. Wylie, K. Prout, J. Chem. Soc. Perkin Trans. 1 1998, 1607-1611.

[17] H. L. Anderson, Chem. Commun. 1999, 2323-2330, and references therein
[18] D. E. Richardson, H. Taube, Inorg. Chem. 1981, 20, 1278-1285.

[19] D. P. Arnold, G. A. Heath, D. A. James, New J. Chem. 1998, 22, 1377-1387.

Received: March 20, 2008 Published online: April 17, 2008 